\title{
Heat Pump Cooling and Greenhouse Microclimates in Open and Confined Greenhouse Systems
}

I. Yildiz

Department of Earth and Env. Sciences

University of Windsor

Windsor, Ontario

N9B 3P4

Canada

\author{
D.P. Stombaugh \\ Department of Agricultural, Food \\ and Biological Engineering \\ The Ohio State University \\ Columbus, $\mathrm{OH} 43210$ \\ U.S.A.
}

Keywords: cucumber microclimate, environmental control, evaporative cooling, transpiration, variable shading, ventilation

\begin{abstract}
The purpose of this study was to determine and compare the performances of conventional and heat pump systems for cooling open and closed loop (confined) greenhouse systems. A dynamic simulation model was developed and validated to predict energy and mass exchanges in a greenhouse as a function of dynamic environmental factors. The model has options to evaluate the effects of location, time of the year, orientation, single and double polyethylene glazings, conventional and heat pump heating and cooling systems, $\mathrm{CO}_{2}$ enrichment, ventilation, variable shading, and the use of night curtains in open and confined greenhouse environments. Variable shading, ventilation and evaporative cooling provided cooling in the conventional system. In the heat pump systems, however, gas fired heat pump units provided cooling. Outputs of the simulation model included both temporal and vertical distribution of air, leaf, floor and cover temperatures, $\mathrm{CO}_{2}$, relative humidity, solar radiation, and photosynthetically active radiation in addition to the dynamics of photosynthesis, respiration, transpiration, energy and $\mathrm{CO}_{2}$ use and fixation in the greenhouse. This study concluded that the heat pump system performed very well with a variable shading system meeting the cooling requirements of both open and confined greenhouse systems.
\end{abstract}

\section{INTRODUCTION}

To provide economically optimal micro-environments for plant growth, producers can use or control the number of glazing layers, insulation curtains or screens to reduce long-wave radiation losses at night, reduced or increased ventilation rates, evaporative coolers, and shading devices to control incoming solar radiation. In addition, a gas fired heat pump system, which was developed by Yildiz (1993) and Yildiz et al. (1993) holds promise for reducing winter heating requirements and warm weather cooling loads. These systems involve complex tradeoffs between initial and operating costs for cooling and heating, plant responses to various environmental factors and the strategies used to regulate temperature, humidity and $\mathrm{CO}_{2}$ levels in the crop canopy. Special attention must also be given to the operational strategies associated with the use of heat pumps, especially in maintaining acceptable relative humidity levels within greenhouses.

A dynamic simulation model was developed and validated to provide an accurate prediction of greenhouse energy and moisture exchanges as a function of dynamic environmental factors (Yildiz and Stombaugh (2006)). This model was used to predict and compare cooling loads, water use, and to evaluate the operational strategies associated with cooling using the proposed heat pump (open and confined) and the conventional system.

\section{PROCEDURES}

Weather File January, April, and July 2003 weather files for Delaware (latitude $40^{\circ} 17^{\prime} \mathrm{N}$, 
longitude $83^{\circ} 05^{\prime} \mathrm{W}$ ), Ohio, U.S.A. were used to represent winter, spring, and summer in the simulations, respectively. Simulations were performed starting at the beginning of the fifth day and ended at the end of 29th day of the month providing a 25-day simulation.

\section{Greenhouse Characteristics and Cooling}

A dynamic computer simulation model to determine greenhouse microclimates for cucumber crop was developed and validated. The theoretical approach, model validation, and detailed greenhouse characteristics were reported earlier by Yildiz and Stombaugh (2006). Table 1 presents some important greenhouse characteristics. The heat pumps evaluated were 3-ton gas fired units, and to provide multiposition proportional control it was assumed that three units were used in each greenhouse. Along with variable shading and ventilation, an evaporative cooler was employed for cooling the conventional (CON) greenhouse. Outdoor air was used in the evaporative cooling system, and it was assumed that the air at the evaporative cooler outlet was fully saturated. In the open (OHP) and closed loop heat pump (CHP) systems, however, in addition to the variable shading system, heat pump units provided the cooling requirements. Indoor air was recirculated and introduced back to the inside at a lower temperature using an overhead plastic tube for the air distribution. Two shading cloths with transmissivities of 0.75 and 0.50 were used to reduce the cooling loads. The use of these shading cloths provided shading levels of $25 \%, 50 \%$ and $62.5 \%$ by using them individually or together. In the open systems (CON and OHP), ventilation was provided by two fans, one with a fixed flow rate to provide a minimum level $\left(0.01 \mathrm{~m}^{3} \mathrm{~s}^{-1} \mathrm{~m}^{-2}\right)$ of air exchange at all times, and the other one with a variable flow rate (with a maximum rate of $0.08 \mathrm{~m}^{3} \mathrm{~s}^{-1} \mathrm{~m}^{-2}$ ).

\section{Operational and Control Strategies}

Based on the indoor air temperature, the control system operated in either the heating or cooling mode. If the system was in heating mode and if heating was required, the ventilation rate was set to the minimum rate. The cooling mode operated in two steps. The first step was to reduce the cooling load using a variable shading system and to cool the inside air by increasing ventilation rates. If the first step in cooling could not handle the cooling load, then the second step was activated, in which the heat pump units (OHP) or evaporative cooling system (CON) provided the cooling. Inside relative humidity in the conventional system was controlled indirectly by the temperature control. In the open loop heat pump system, however, additional relative humidity control was provided. When the inside relative humidity levels exceeded $80 \%$, additional ventilation was introduced to decrease inside relative humidity. In the cooling mode of the closed system, there was only one step unlike the conventional and open loop systems, which had twostep cooling systems. Here, no cooling was provided by ventilation; instead, it was done by the three heat pump units providing a multiposition proportional control, when possible, after reducing the cooling load using the variable shading system. The operation of the shading system was the same as in the other two systems. Here, either the cooling units or the dehumidifier (the first heating unit) controlled inside relative humidity.

\section{RESULTS AND DISCUSSION}

Figurel shows the diurnal changes in solar radiation, relative humidity and temperature regimes in a conventional, open loop and closed loop heat pump greenhouse systems on a spring day. Temperature fluctuations were observed early in the morning because of the first heating unit's turning on and off due to low outside air temperatures. The shading system was operated between the hours of 11:00 and 17:00 to reduce the cooling loads. Figurela shows that, in the conventional greenhouse, a maximum indoor temperature of $26^{\circ} \mathrm{C}$ was maintained on this particular day. Figure $1 \mathrm{~b}$ shows the diurnal changes in predicted greenhouse climatological variables in the open loop heat pump greenhouse on the same day. Except for several small but significant differences, the results were not much different from those predicted for the conventional system. The shading system was activated right before 12:00 noon in this system, whereas it was 
initiated immediately after 10:00 in the conventional system. This resulted from the differences in inside air temperatures. The inside air temperature reached higher levels earlier in the conventional system. The reason for different inside air temperature regimes in the two systems was the fact that higher ventilation rates were used in the open loop heat pump system when the relative humidity reached $80 \%$ around 8:00 in the morning (Fig.1b). In the conventional system, nothing was initiated when the relative humidity reached levels higher than $80 \%$ at these hours. The relative humidity was only controlled indirectly through the control of the air temperature in the conventional system. As mentioned earlier, additional control (increased ventilation rates) was employed to control the relative humidity at about $80 \%$ in the open loop heat pump system. In the closed loop system, during the day, the inside air temperature fluctuated due to the operation of the cooling units, while nighttime fluctuations caused by the heating units (Fig.1c). The indoor climatic conditions were maintained within the desired set points in all systems.

Figure $2 \mathrm{a}$ shows operation of the control system in a conventional greenhouse system on a summer day, which represents the operational diversity of the simulation model. Solar radiation inside the greenhouse was maintained at an average of $250 \mathrm{~W} / \mathrm{m}^{2}$ with a minimum of $200 \mathrm{~W} / \mathrm{m}^{2}$ where it was possible. Indoor temperature was maintained at $18^{\circ} \mathrm{C}$ at night and $20^{\circ} \mathrm{C}$ during the day. Inside relative humidity was only influenced indirectly via control of the inside temperature in this system. The relative humidity was below $90 \%$ during the day, and reached $95 \%$ at night. On this particular day, shading and evaporative cooling were necessary to maintain the indoor climatic variables at desired levels. An increase in outside solar radiation in the morning resulted in the use of $25 \%$ shading first, then $50 \%$ shading, and finally $62.5 \%$ shading (both shading cloths) by noon. Since shading only was not sufficient to keep the inside climatic variables at desired levels, evaporative cooling was necessary from noon until late afternoon. Evaporative cooling was used 45\% of the time between 13:00 and 14:00 in the afternoon.

In the open loop heat pump system on spring days, the inside solar radiation level was maintained at an average value of $250 \mathrm{~W} / \mathrm{m}^{2}$. Because of the outside climatic conditions early in the morning, supplemental heating was sometimes needed to maintain inside air temperature at $18^{\circ} \mathrm{C}$. Most of the time, the shading system was not operated at all in the morning to allow more solar radiation into the greenhouse in an effort to reduce the supplemental heating requirements. When the outside air temperature reached approximately $25^{\circ} \mathrm{C}$ in the afternoon, while the outside solar radiation reached $700 \mathrm{~W} / \mathrm{m}^{2}$, the shading system was operated in an effort to reduce the cooling loads. With the shading system operational and an increased ventilation rate, on some days, it was not necessary to provide mechanical cooling. The inside relative humidity was also maintained at acceptable levels.

Figure $2 b$, on the other hand, shows operation of the control system in the confined greenhouse system on a different spring day to illustrate a wide diversity in operational strategies used in this system. Inside solar radiation and air temperatures were maintained at an average of $250 \mathrm{~W} / \mathrm{m}^{2}$, and $18^{\circ} \mathrm{C}$ (nighttime) and $20^{\circ} \mathrm{C}$ (daytime), respectively. The outside air, due to no ventilation, did not affect indoor relative humidity in this greenhouse system. Figure 2c also shows the first heating unit's operation as a dehumidifier to remove the excess moisture. The dehumidification process was successful keeping the inside relative humidity levels at a set point of $80 \%$ with some overshooting. The relative humidity levels were maintained below $90 \%$ throughout the day. During the day, shading and heat pump cooling was necessary to maintain the indoor climatic variables at desired levels. On this particular day, one heat pump unit was sufficient to manage the cooling loads. Shading levels ranged from $25 \%$ to $62.5 \%$ (full shading). Even though full shading was operational 100\% of the time between 11:00 and 13:00, it was not sufficient to handle the cooling loads during these hours. One heat pump unit was operated $100 \%$ of the time during these hours, in addition to the shading.

Figure 3 presents the long-term operation of the simulation model and behavior of climatic variables, hourly water use, collection, and energy consumption rates per unit ground area in the conventional, open and closed loop heat pump greenhouse systems for 
10 successive days in summer. These 10-day simulations were obtained from 25-day simulation runs ignoring the first 6 and last 9 days of the simulations. In the conventional system, water was used for both transpiration and evaporative cooling (Fig. 3a), whereas in the heat pump greenhouse systems water was used for transpiration only, some of it was recovered in the open system and almost all in the confined system (Fig. 3b).

Table 2 summarizes the daily averages of energy consumption for cooling and water consumption in conventional, open loop heat pump, and closed loop heat pump systems in winter, spring, and summer. When both heating and cooling seasons are considered, it was determined that, in the conventional system, $99.5 \%$ of the energy consumption was used for heating, while the remaining portion $(0.5 \%)$ was used for ventilation. In the open loop heat pump system, $94.2 \%$ of the total energy consumption was used for heating, while $3.1 \%$ and $2.7 \%$, respectively, were used for ventilation and heat pump cooling. In the closed loop system, $70 \%$ of the total energy consumption was used for heating, while 30\% was used for cooling. The energy used for cooling was much less than the energy used for heating, because the shading reduced the required cooling loads. Also, the plants themselves are biological air-conditioners and can provide much of their own cooling.

Table 2 also shows that higher transpiration rates were predicted in winter than in spring and summer in the conventional and open loop heat pump systems, even though lower solar radiation levels were observed in winter. Low outside relative humidity in winter was the driving force for the increased transpiration rates. In summer, the transpiration rates in the open loop heat pump system were higher than those in the conventional system due to the smaller vapor pressure deficits in the conventional system as a result of evaporative cooling. The variation in transpiration rates in the closed loop system with respect to different seasons, however, was mostly the result of increased solar radiation rather than the vapor pressure deficit. The transpiration rates in this system were lower than those in the other two systems due to the higher inside relative humidity levels. Average daily transpiration rates of winter, spring and summer were 2.09, 2.02, and $1.02 \mathrm{~kg}$ day $^{-1} \mathrm{~m}^{-2}$ in the conventional, open loop, and closed loop heat pump systems, respectively. In addition to the transpiration, water was also used for evaporative cooling in the conventional system. In the closed loop system, almost all the transpired water was recovered on the coils, making the overall water consumption in this system essentially zero. Thus, the closed loop system was the most water conserving system, while the conventional system used the most water of all the systems in this study. When all three systems are compared with respect to the total energy consumption (both heating and cooling) the closed loop system was the most energy conserving system, while the conventional system used the most energy of all the systems. If the three systems are to be compared with respect to the energy consumption for cooling only, based on the average daily energy consumption (winter, spring, and summer values averaged together), the closed loop system had the highest energy consumption for cooling $\left(2.48 \mathrm{MJ} \mathrm{day}^{-1} \mathrm{~m}^{-}\right.$ ${ }^{2}$ ), while the open loop and conventional systems had the consumptions of $0.66 \mathrm{MJ}^{-1} \mathrm{day}^{-1}$ $\mathrm{m}^{-2}$ and $0.12 \mathrm{MJ}$ day $^{-1} \mathrm{~m}^{-2}$, respectively.

\section{CONCLUSIONS}

This study concluded that greenhouse operation with the heat pump system has a great potential for enormous energy and water savings, as well as dehumidification. Closed loop greenhouse operation with a heat pump system would also make it easier to control the humidity and keep high $\mathrm{CO}_{2}$ levels, while reducing the risk of insects and diseases within the confined greenhouse environment. The heat pump system performed very well with a variable shading system significantly conserving both energy and water when both heating and cooling are considered. A combination of open and closed loop systems would be the most energy and water conserving system, operating the system as a closed loop system in fall, winter and spring, and as an open loop system in summer. However, when only the cooling season is considered, the commercial feasibility of using a heat pump system depends on other savings such as savings in water and $\mathrm{CO}_{2}$ use. 


\section{ACKNOWLEDGEMENTS}

American Society of Heating, Refrigerating, and Air-Conditioning Engineers, Inc. and Ohio Super Computing Center provided partial funding for this study.

\section{Literature Cited}

Yildiz, I. 1993. A performance study of a Rankine cycle driven heat pump system. M.S. Thesis. The Ohio State University, Columbus, Ohio, U.S.A.

Yildiz, I., Lin, C., and Christensen, R.N. 1993. A performance study of a Rankine cycle driven heat pump system. AES-Vol. 29, Heat Pump and Refrigeration Systems Design, Analysis, and Applications. ASME: 9-18

Yildiz, I. and Stombaugh, D.P. 2006. Dynamic modeling of microclimate and environmental control strategies in a greenhouse coupled with a heat pump system. Models for Plant Growth, Environmental Control, and Farm Management in Protected Cultivation - HortiModel 2006. October 29-November 2, Wageningen, The Netherlands (in press by Acta Hort).

\section{Tables}

Table 1. Greenhouse characteristics used in the simulation model (CON: Conventional system; OHP: Open loop heat pump; CHP: Closed loop heat pump system).

\begin{tabular}{lc}
\hline Length & $7.5 \mathrm{~m}(\mathrm{CON} \&$ OHP) and $25.0 \mathrm{~m}(\mathrm{CHP})$ \\
Width & $7.50 \mathrm{~m}$ \\
Height at eaves & $2.50 \mathrm{~m}$ \\
Height at ridges & $4.50 \mathrm{~m}$ \\
Crop row orientation & North - South \\
Distance between plant rows & $0.75 \mathrm{~m}$ \\
Floor surface material & Reflective mulch \\
Glazing & Double polyethylene \\
\hline
\end{tabular}

Table 2. Daily energy consumption and water use in conventional (CON), open loop (OHP), and closed loop heat pump (CHP) systems in winter, spring, and summer.

\begin{tabular}{|c|c|c|c|c|c|c|c|c|c|}
\hline & \multicolumn{3}{|c|}{ WINTER } & \multicolumn{3}{|c|}{ SPRING } & \multicolumn{3}{|c|}{ SUMMER } \\
\hline & CHP & $\mathrm{OHP}$ & $\mathrm{CON}$ & $\mathrm{CHP}$ & $\mathrm{OHP}$ & $\mathrm{CON}$ & $\mathrm{CHP}$ & OHP & $\mathrm{CON}$ \\
\hline \multicolumn{10}{|c|}{ Energy Consumption $\left(\mathrm{MJ}\right.$ day $^{-1} \mathrm{~m}^{-2}$ ) } \\
\hline Heat Pump Cooling & & & & & & & & & \\
\hline Natural Gas & 0.02 & ---- & ----- & 1.94 & ----- & ----- & 5.19 & 0.91 & ---- \\
\hline Fan (Electric) & * & ----- & ----- & 0.05 & ----- & ----- & 0.14 & 0.02 & ----- \\
\hline Pump (Electric) & * & ----- & ----- & 0.03 & ----- & ----- & 0.08 & 0.01 & ----- \\
\hline Subtotal & 0.02 & ----- & ----- & 2.02 & ----- & ----- & 5.40 & 0.94 & ---- \\
\hline Ventilation & ---- & 0.11 & 0.11 & ----- & 0.23 & 0.11 & ---- & 0.71 & 0.13 \\
\hline TOTAL & 0.02 & 0.11 & 0.11 & 2.02 & 0.23 & 0.11 & 5.40 & 1.65 & 0.13 \\
\hline \multicolumn{10}{|c|}{ Water Consumption $\left(\mathrm{kg} \mathrm{H}_{2} \mathrm{O}\right.$ day $\left.^{-1} \mathrm{~m}^{-2}\right)$} \\
\hline Transpiration & 0.85 & 2.52 & 2.54 & 1.05 & 2.22 & 2.17 & 1.17 & 1.66 & 1.28 \\
\hline Water Recovered & 0.83 & ----- & ----- & 1.04 & ----- & ----- & 1.17 & 0.35 & ----- \\
\hline Evaporative Cooling & ----- & ----- & ----- & ----- & ----- & ---- & ----- & ----- & 0.29 \\
\hline TOTAL & 0.02 & 2.52 & 2.54 & 0.01 & 2.22 & 2.17 & 0.00 & 1.31 & 1.57 \\
\hline
\end{tabular}

* Negligible amount. 


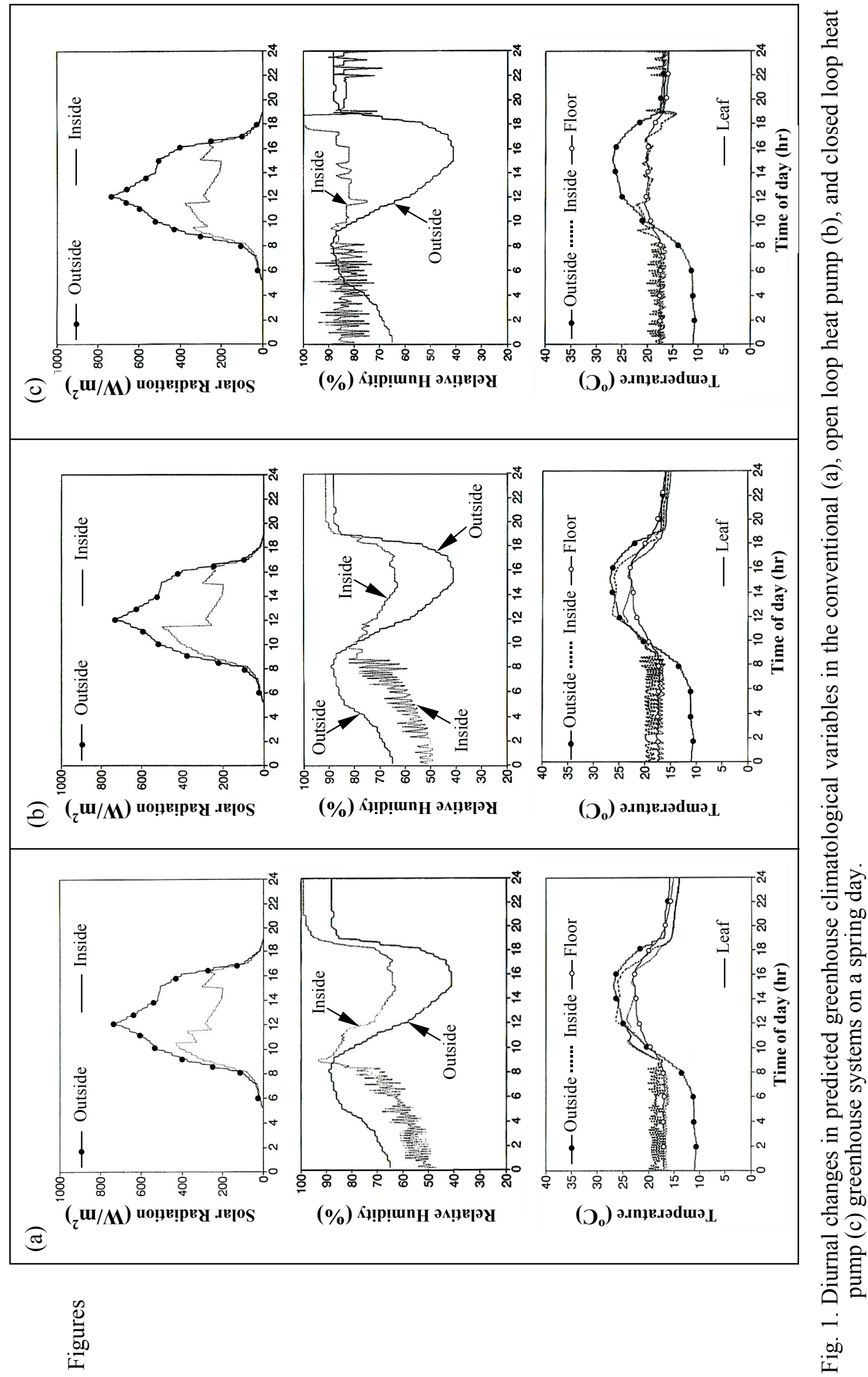




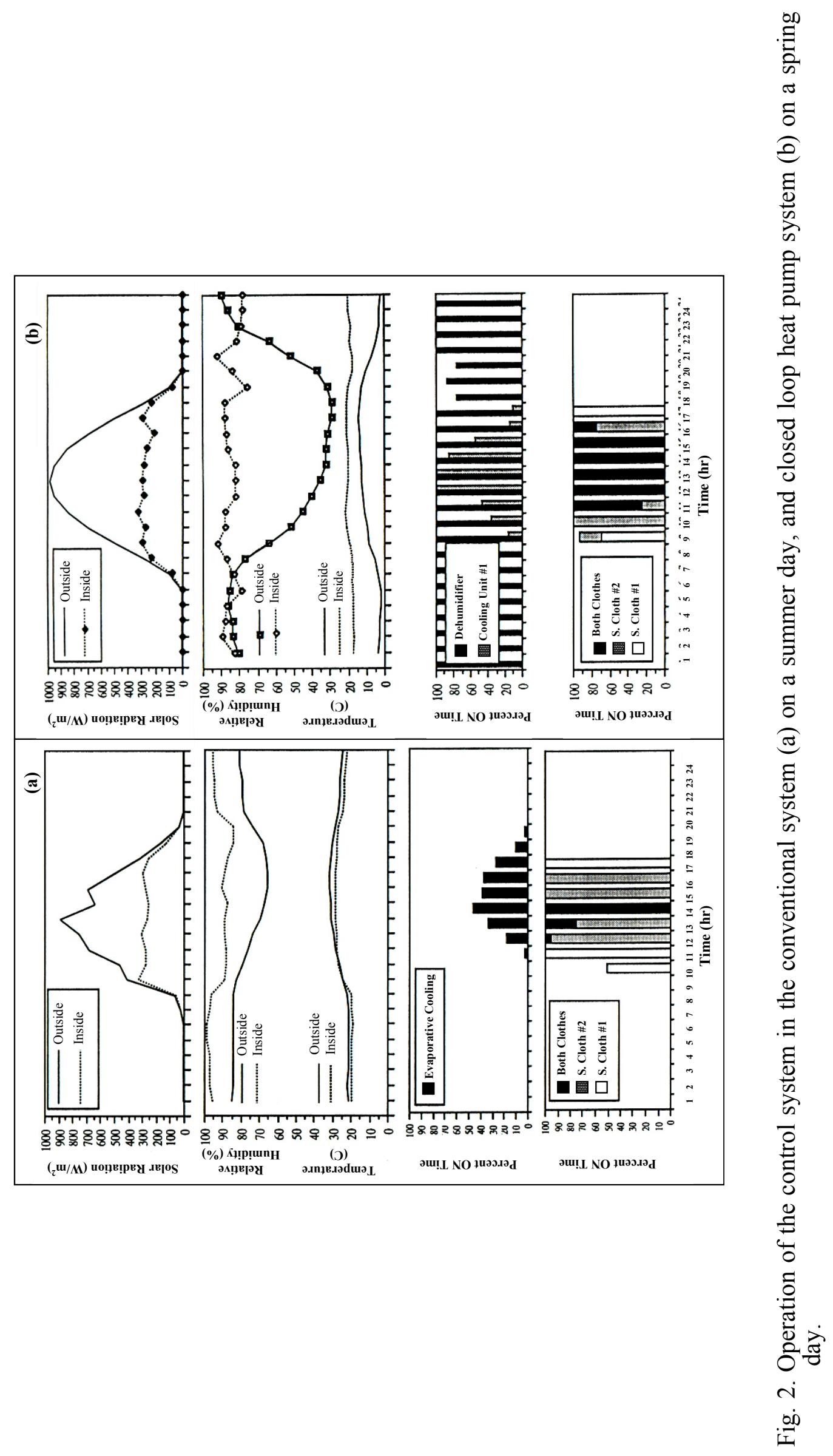




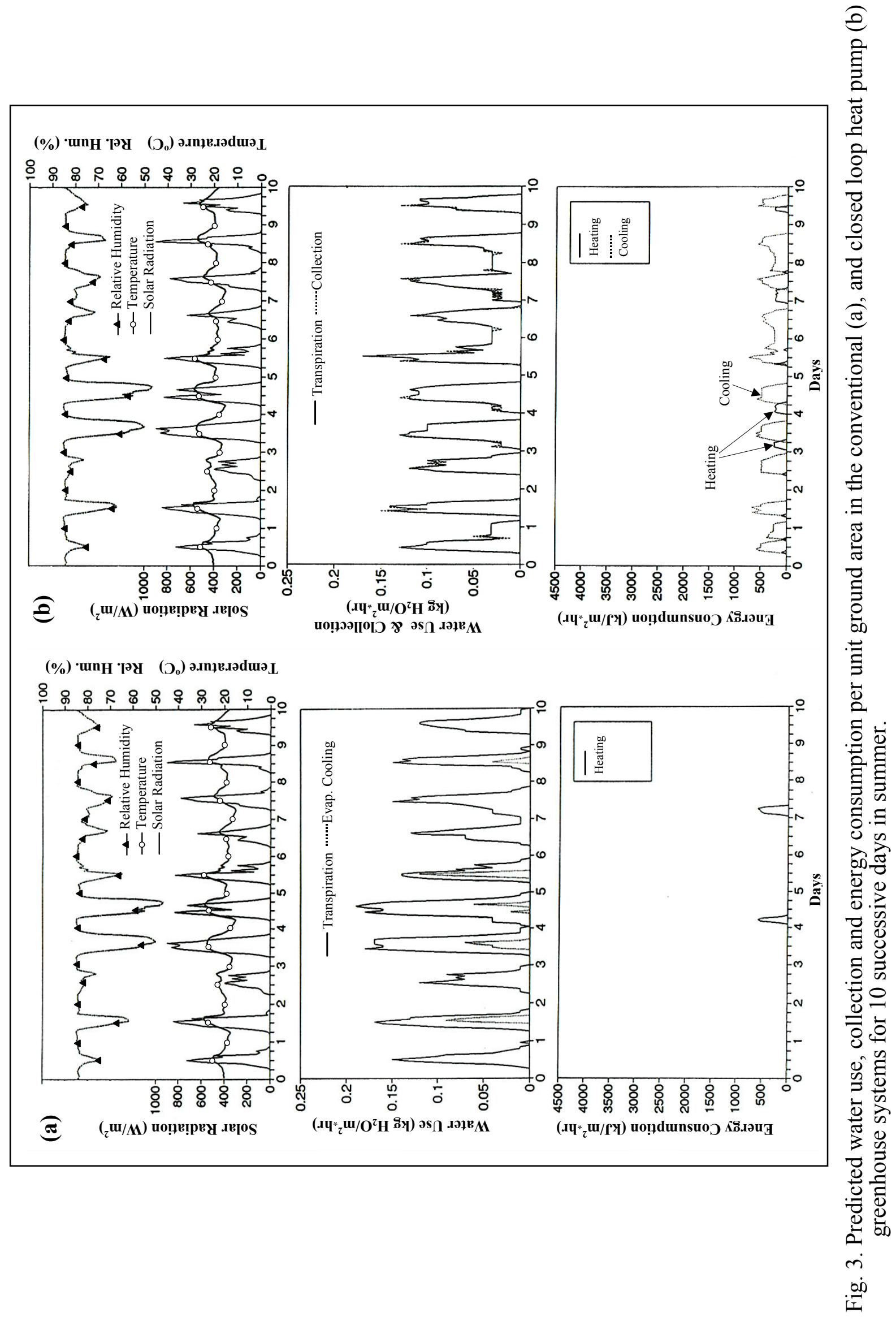

